\title{
МЕТОДИКА СОГЛАСОВАНИЯ ЦЕН НА ПРОДУКЦИЮ И УСЛУГИ В СИСТЕМЕ ЗАКУПОК ДЛЯ ОРГАНИЗАЦИИ МТО ВС РФ, ДРУГИХ ВОЙСК, ВОИНСКИХ ФОРМИРОВАНИЙ И ОРГАНОВ
}

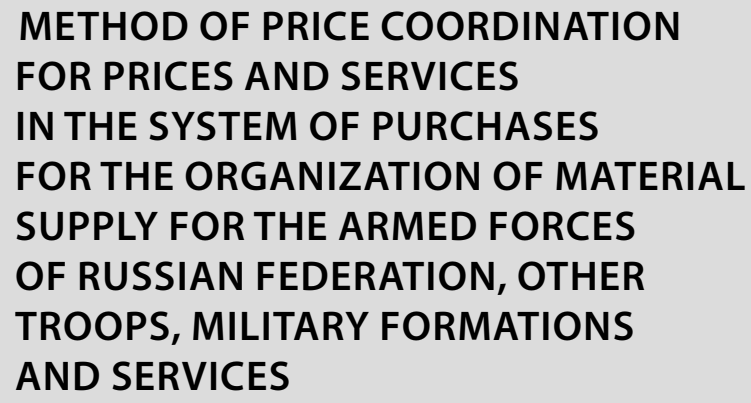

METHOD OF PRICE COORDINATION FOR PRICES AND SERVICES

IN THE SYSTEM OF PURCHASES

FOR THE ORGANIZATION OF MATERIAL SUPPLY FOR THE ARMED FORCES OF RUSSIAN FEDERATION, OTHER TROOPS, MILITARY FORMATIONS AND SERVICES

\section{Ruchenin}

Summary. The paper explains the nature of the method of coordination of prices for products and services for the system of purchases for the organization of material supplies for the Armed Forces of Russian Federation, other troops, military formations and services for the material and technical supplies for the army on the basis of the Federal Law of 05 April 2013 No 44-FZ "On the contract system in the sphere of purchases of products and services for the state and municipal needs" and ways of implementation of this method

Keywords: method of coordination, prices of products and services, purchases for organizations of material supply, state purchases, optimization of the process of state purchases.
B соответствии с реализуемыми принципами государственной политики дальнейшее развитие системы МТО ВС РФ должно осуществляться путем реализации комплекса мероприятий, предусматривающих гарантированное удовлетворение потребностей войск (сил) в материальных средствах, ВBCT, продукции производственно-технического назначения и услугах. Это требует формирования системы закупок материальных средств (MC) и услуг, включающей теоретические положения и практические рекомендации по выбору поставщиков всех видов материальных средств и услуг, согласования справедливых цен на продукцию и услуги в соответствии с рыночный конъюнктурой и условиями поставки, создания соответствующих форм кооперации взаимодействующих с системой МТО предприятий и организаций экономического комплекса (ЭКС), структурных подразделений ОПК, участвующих в поставках продукции по государственному оборонному заказу (ГОЗ) [1, 4, 13].

\author{
Рученин Игорь Анатольевич \\ Адъюнкт, Военная академия материально- \\ технического обеспечения им. генерала армии \\ А.В. Хрулева, г. Санкт-Петербург \\ yunikiti@yandex.ru
}

Аннотация. В статье раскрываются сущность методики согласования цен на продукцию и услуги в системе закупок для организации МТО ВС РФ, других войск, воинских формирований и органов в интересах материально-технического обеспечения войск (сил) на основании Федерального закона от 5 апреля 2013 г. N44-\$3 «0 контрактной системе в сфере закупок товаров, работ, услуг для обеспечения государственных и муниципальных нужд» и направления реализации данной методики.

Ключевые слова: методика согласования, цены на продукцию и услуги, закупки для организаций МТ0, госзакупки, оптимизация процесса госзакупок.

Сущность предлагаемой методики заключается в оптимизации процесса госзакупок и качества закупаемых материальных средств и услуг на основе минимизации затрат на приобретение и поставку МС от предприятий ЭКС и ОПК на склады ВО (ПЛК) и в соединения, части и организации (СЧО), а также на предоставляемые сторонними организациями услуги по службам МТО (например, хранение и доставка МС, организация питания и банно-прачечного обслуживания личного состава, заправка и ремонт ВВСТ и др.) при обеспечении их требуемого качества. Такая система закупок и поставок в СМТО позволяет одновременно оптимизировать не только показатели процесса госзакупки, но и показатели качества поставляемых ВВСТ, МС и услуг [10, 11, $12]$.

При планировании закупок необходимо учитывать, что стоимость МС включает в себя все расходы на закупку сырья, его переработку и производство готовой 
Таблица 1. Содержание основных процессов и параметры взаимодействия органов МТО и поставщиков продукции и услуг [4].

\begin{tabular}{|c|c|c|c|c|}
\hline $\begin{array}{l}\text { № } \\
\Pi / \Pi\end{array}$ & $\begin{array}{l}\text { Органы } \\
\text { взаимодействия }\end{array}$ & $\begin{array}{l}\text { Основные } \\
\text { бизнес-процессы }\end{array}$ & $\begin{array}{l}\text { Основные } \\
\text { логистические } \\
\text { процессы }\end{array}$ & Основные параметры \\
\hline 1 & $\begin{array}{l}\text { Госзаказчик } \\
\text { (СМТО) }\end{array}$ & $\begin{array}{l}\text { 1. Закупка МС } \\
\text { 1.1. Формирование } \\
\text { ценовой политики, } \\
\text { объема и рациональной } \\
\text { стоимости госзакупок МС }\end{array}$ & $\begin{array}{l}\text { Создание } \\
\text { запасов МС }\end{array}$ & $\begin{array}{l}\text { 1. Потребность и обеспеченность MC } \\
\text { 2. Требуемый объем госзакупок МС } \\
\text { 3. Выделенные бюджетные средства } \\
\text { 4. Базовая, начальная и оптимальная цена } \\
\text { контракта }\end{array}$ \\
\hline 2 & $\begin{array}{l}\text { Поставщики МС } \\
\text { (производители) }\end{array}$ & $\begin{array}{l}\text { 1.2. Обоснование } \\
\text { рациональной цены } \\
\text { контракта и выбора } \\
\text { поставщиков МС }\end{array}$ & $\begin{array}{l}\text { 1.1. Планирование } \\
\text { поставок МС }\end{array}$ & $\begin{array}{l}\text { 1. Оптовые цены на рынке МС 2. Балансовая } \\
\text { прибыль поставщиков МС и услуг } \\
\text { 3. Характеристики поставщиков }\end{array}$ \\
\hline 3 & $\begin{array}{l}\text { Поставщики МС } \\
\text { (посредники) }\end{array}$ & $\begin{array}{l}\text { 1.3. Обоснование } \\
\text { рациональной } \\
\text { балансовой } \\
\text { прибыли и выбора } \\
\text { посредников (дилеров, } \\
\text { дистрибьюторов, 2 PL и } 3 \\
\text { PL - провайдеров) } \\
\end{array}$ & 1.2. Закупка MC & $\begin{array}{l}\text { 1. Тарифы на услуги посредников в данном } \\
\text { регионе } \\
\text { 2. Балансовая прибыль посредников } \\
\text { 3. Характеристики посредников }\end{array}$ \\
\hline 4 & $\begin{array}{l}\text { Потребители } \\
\text { (ЦМТО) }\end{array}$ & $\begin{array}{l}\text { 2. Поставка МС } \\
\text { 2.1. Обоснование } \\
\text { рациональных текущих } \\
\text { и страховых запасов } \\
\text { 2.2. Обоснование } \\
\text { рационального объема } \\
\text { поставки МС } \\
\end{array}$ & 1.3. Поставка MC & $\begin{array}{l}\text { Размеры текущих и страховых запасов } \\
\text { Нормы эшелонирования запасов } \\
\text { Объем поставки } \\
\text { Затраты на создание запасов }\end{array}$ \\
\hline 5 & $\begin{array}{l}\text { Потребители } \\
\text { (склады ВО, ПЛК) }\end{array}$ & $\begin{array}{l}\text { 3. Содержание запасов } \\
\text { МС } \\
\text { 3.1. Обоснование } \\
\text { рационального } \\
\text { количества, размещения } \\
\text { складов и способа } \\
\text { хранения. } \\
\text { 3.2. Обоснование } \\
\text { рациональных } \\
\text { показателей } \\
\text { функционирования } \\
\text { объектов хранения МС } \\
\end{array}$ & $\begin{array}{l}\text { Хранение } \\
\text { запасов МС }\end{array}$ & $\begin{array}{l}\text { 1. Число и размещение складов, филиалов } \\
\text { (ПЛК) } \\
\text { 2. Емкость, площадь и мощность складов } \\
\text { 3. Производительность приема и выдачи } \\
\text { МС } \\
\text { 4. Грузооборот склада } \\
\text { 5. Внутри складская транспортная работа } \\
\text { 6. Тарифы или затраты на хранение }\end{array}$ \\
\hline 6 & Потребители (СЧО) & $\begin{array}{l}\text { 4. Транспортировка } \\
\text { 4.1. Обоснование } \\
\text { рациональных } \\
\text { планов и способов } \\
\text { транспортировки } \\
\text { (доставки) МС }\end{array}$ & Доставка MC & $\begin{array}{l}\text { 1. Потребность в МС } \\
\text { 2. Размещение (расстояние) относительно } \\
\text { складов и поставщиков } \\
\text { 3. Транспортная работа } \\
\text { 4. Тарифы или затраты на транспортировку }\end{array}$ \\
\hline
\end{tabular}

продукции, контроль ее качества и надежности, поставку на склады ВО (ПЛК) или доставку в СЧО. Заказчик (органы МТО) стремится получить продукцию заданного качества в установленные сроки по минимальной цене [9]. Исполнитель (производитель, поставщик), в свою очередь, заинтересован в большем объеме прибыли, в том числе путем снижения себестоимости продукции в ущерб качеству сырьевой составляющей. Более того, специфика ГОЗ и порядок деятельности большинства предприятий ОПК не предполагают открытого распространения информации (значительный объем информации о ГОЗ является закрытым).

Основными направлениями решения задачи согласования цен межу производителем (поставщиком), заказчиком и потребителем являются: оценивание ка- 
Таблица 2. Параметры и показатели эффективности процесса закупок МС и услуг в СМТО

\begin{tabular}{|c|c|c|}
\hline Параметры процесса закупок & $\begin{array}{l}\text { Качественные показатели } \\
\text { работы }\end{array}$ & $\begin{array}{l}\text { Кколичественные показатели } \\
\text { работы }\end{array}$ \\
\hline $\begin{array}{l}\text { 1. Производственные мощности } \\
\text { поставщиков }\end{array}$ & $\begin{array}{l}\text { Способность поставщиков } \\
\text { обеспечивать потребности в ВВСТ, } \\
\text { продукции двойного и гражданского } \\
\text { назначения }\end{array}$ & $\begin{array}{l}\text { полнота удовлетворения потребности СЧО в МС; } \\
\text { своевременность выполнения заказа; } \\
\text { объем (наличие) запасов; } \\
\text { дефицит запасов МС; } \\
\text { качество МТС или количество возвратов }\end{array}$ \\
\hline $\begin{array}{l}\text { 2. Производительность } \\
\text { логистической } \\
\text { инфраструктуры }\end{array}$ & $\begin{array}{l}\text { Соответствие производственных } \\
\text { возможностей элементов складской } \\
\text { и транспортной инфраструктуры } \\
\text { производить конкурентоспособную } \\
\text { продукцию и перерабатывать } \\
\text { требуемые объемы МС } \\
\end{array}$ & $\begin{array}{l}\text { производительность складского подъемно- } \\
\text { транспортного и технологического оборудования; } \\
\text { пропускная способность транспортных } \\
\text { коммуникаций; } \\
\text { количество обработанных заказов в единицу времени; } \\
\text { грузовые отправки на единицу складских мощностей. }\end{array}$ \\
\hline $\begin{array}{l}\text { 3. Надежность } \\
\text { поставщиков МС }\end{array}$ & $\begin{array}{l}\text { Способность поставщиков МС } \\
\text { выполнять свои функции в течение } \\
\text { заданного времени обеспечить } \\
\text { (безотказность работы) } \\
\end{array}$ & $\begin{array}{l}\text { выполнение графиков поставок; } \\
\text { коэффициент удовлетворенности потребителей; } \\
\text { удовлетворение клиента с позиций «совершенного } \\
\text { заказа». }\end{array}$ \\
\hline $\begin{array}{l}\text { 4. Скорость реакции поставщиков } \\
\text { МС }\end{array}$ & $\begin{array}{l}\text { Скорость исполнения } \\
\text { заказа - способность поставщиков } \\
\text { МС оперативно удовлетворять } \\
\text { потребности в продукции, } \\
\text { выполнения работ, оказания услуг } \\
\end{array}$ & $\begin{array}{l}\text { время подготовки и комплектации заказа; } \\
\text { время исполнения заказа; } \\
\text { время доставки заказа потребителю; } \\
\text { длительность логистических циклов. }\end{array}$ \\
\hline 5. Затраты в системе закупок & $\begin{array}{l}\text { Операционные логистические } \\
\text { издержки в системе закупок }\end{array}$ & $\begin{array}{l}\text { общие затраты на закупку и поставку } \\
\text { (транспортировку) МС; } \\
\text { общие и удельные затраты на хранение MC; } \\
\text { общие затраты на доставку MC; } \\
\text { общие затраты на управление запасами и возвраты } \\
\text { MC; } \\
\text { общие и удельные логистические издержки. }\end{array}$ \\
\hline
\end{tabular}

чества и надежности при выборе поставщиков МС и услуг для СЧО ВО; обоснование рациональной цены при заключении контрактов на их поставку; оптимизация логистических издержек при закупке и доставке МС конечным потребителям.

Анализ содержания и основных параметров (табл. 1) взаимодействия (кооперации) оргструктур СМТО и поставщиков показал, что в основе выбора механизмов согласования цен должны иметь место факторы ценообразования на продукцию и услуги. В особенности это касается структурных подразделений нижнего звена взаимодействующих структур в системе закупок.

Важным требованием к качеству работы поставщиков в системе закупок СМТО являются такие показатели их деятельности, как производственно-логистические мощности, надежность, быстрота реакции, логистические издержки.

В целях исключения случаев установления экономически, технологически и (или) иным образом не обоснованной цуены на продукцию, поставляемую в СМTO, превышающей цену, сложившуюся на соответствующем товарном рынке, необходима разработка методики обоснования согласования цен в процессе госзакупок материальных средств и услуг.

Прежде чем приступить к изложению методики, необходимо сделать ряд пояснений, раскрывающих ее основные положения.

В основе разработки подхода к обоснованию рациональной цены с одной стороны должны находиться процедуры оптимизации поставок, минимизирующие затраты на приобретение и доставку материальных средств и услуг. С другой - способы обеспечения их требуемого качества. Иными словами требуется одновременно оптимизировать не только цены на поставляемые материальные средства и услуги, но и показатели их качества на требуемом уровне в целях обеспечения боеготовности войск (сил). Основные показатели качества работы поставщиков, подлежащие анализу в процессе их выбор, приведены в табл. 2.

При этом необходимо учесть, что размещение ГОЗ возможно как на конкурсной основе в соответствии Федеральными законами от 05.04.2013 N44-Ф3, от 18.07.2011 № 223 Ф3, так и у единственного поставщика (п. 7 части 1 статьи 93 Федерального закона от 05.04.2013 N44-Ф3). 
В рамках предлагаемой методики госзаказчик может разработать такую схему поставок, при которой себестоимость продукции военного назначения, материальных средств, услуг и цена их качества будут оптимизированы. В процессе взаимодействия все субъекты процесса закупок будут стремиться к достижению таких условий поставок материалов, производства продукции и услуг, которые позволят им существенно снизить свои затраты, улучшить производительность, повысить качество продукции и услуг.

Для ГОЗ и закупок в интересах СМТО характерно то, что если обычно цена на товарном рынке - это цена сделки, добровольно признанная сторонами справедливой, когда реальные затраты продавца и себестоимость никого из покупателей не интересует, то в рамках государственного оборонного заказа вопросы ценообразования жестко регламентированы.

В условиях конкуренции прогноз ценообразования в процессе госзакупок продукции и услуг в интересах СМТО ВС РФ позволяет на стадии поиска потенциальных поставщиков и подготовки к заключению контракта определить некоторую базовую цену, «отталкиваясь» от которой заказчику необходимо вести переговоры во время проведения торгов. Указанные обстоятельства требуют разработки комплексного, оптимизационно-квалиметрического подхода к моделированию качества закупок материальных средств и услуг в СМТО ВС РФ и определению базовой ияены.

Согласование интересов заказчика, поставщика (производителя) и потребителя материальных средств и услуг возможно за счет определения базовой цены на основе комплексного применения оценки стоимости продукции на основе затратного, доходного и сравнительного (рыночного) подходов (рис. 1) [8].

На первом этапе расчет базовой цены продукции осуществляется с применением методов затратного подхода, который основывается на расчете себестоимости продукции, прибыли и торгово-снабженческих надбавок.

$$
C_{i}^{z}=s_{i}+p_{i}+a_{i}
$$

где $C_{i}^{z}$ - цена единицы $i$ - го вида продукции (услуг), рассчитанная затратным подходом, руб.;

$s_{i}$ - себестоимость единицы $i$ - го вида продукции (услуг), руб.;

$p_{i}$ - прибыль на единицу $i$ - го вида продукции (услуг), руб.;

$a_{i}$ - торгово-снабженческие надбавки на единицу $i$ - го вида продукции (услуг), руб.
Необходимо отметить, что применение этого подхода базируется на предположении о том, что покупатель не заплатит за продукцию (услуги) больше, чем за продукцию (услуги) аналогичной полезности. Основным недостатком затратного подхода является то, что используя экономическую информацию о нормах расхода и иченах ресурсов, полученную от изготовителя или продавиа, моделируется процесс затратного иченообразования и получается в итоге затратная цеену предложения. Поэтому оценка стоимости, как правило, получается завышенной.

В ходе второго этапа расчет базовой цены продукции выполняется по доходному подходу. Необходимо отметить, что применение доходного подхода в отношении материальных средств и услуг, поставляемых в СМТО ВС РФ, ограничивается тем, что поставляемая продукция не используется в коммерческих целях. Поэтому величина дохода может быть оценена только через разность затрат на эксплуатацию (применение) существующих и поставляемы образцов ВВСТ, материальных средств, производственно-технической продукции. Однако этот подход дает возможность заказчику выбрать наиболее эффективную продукцию для поставки в СЧО.

В случае возможности «получения доходов» (снижение затрат на эксплуатацию, ремонт или возможности выражения эффекта в стоимостной форме) для определения базовой цены можно использовать следующую зависимость

$$
\mathrm{Q}=\sum_{k=0}^{n} \frac{R_{k}}{\left(1+\Pi_{e=1}^{m_{k}} i_{e_{k}}\right)^{k}}-\sum_{k=0}^{n} \frac{z_{k}}{\left(1+\Pi_{e=1}^{m_{k}} i_{e_{k}}\right)^{k}},
$$

где $R_{k}$ - эффект от закупки материальных средств (услуг) в $k$-м временном периоде (году, полугодии, квартале, месяце), руб.;

$i_{e_{k}}$ - ставка дисконта в $e$-м подпериоде $k$-го временного периода (года);

$m_{k}$ - число периодов (месяцев, кварталов) фиксации ставки дисконта в $k$-м временном периоде (году);

$Z_{k}$ - затраты на эксплуатацию (ремонт, утилизацию и др.) в $k$-м временном периоде.

Зависимость (2) характеризует стоимость жизненного цикла закупаемой продукции от момента ее приобретения и до утилизации [14, 15]. Следует иметь ввиду, что доходный подход дает верхнюю предельную цену, на которую может согласиться заказчик, руководствуясь здравым смыслом сопоставления своих сегодняшних затрат с будущими выгодами (например, на эксплуатацию и ремонт). Оценка на основе доходного подхода дает несколько заниженнылй результат. 
1. Расчет базовой цены продукции с применением методов затратного подхода, который основывается на расчете себестоимости материальных средств, продукции (услуг)., прибыли и торгово-снабженческих надбавок.

где $C_{i}^{Z}$ - цена единицы $i$-го вида продукции (услуг), рассчитанная затратным подходом, руб.;

$s_{i}$ - себестоимость единицы $i-$ го вида продукции (услуг), руб.;

$p_{i}-$ прибыль на единицу $i-$ го вида продукции (үслүг), руб.;

$a_{i}$ - торгово-снабженческие надбавки на единицу $i$ - го вида продукции (услуг), руб.

2. Расчет базовой цены продукции с применением методов доходного подхода, который основывается на расчете стоимости жизненного цикла материальных средств, продукции (услуг).

$$
Q=\sum_{k=0}^{n} \frac{R_{k}}{\left(1+\prod_{e=1}^{m_{k}} i_{e_{k}}\right)^{k}}-\sum_{k=0}^{n} \frac{Z_{k}}{\left(1+\prod_{e=1}^{m_{k}} i_{e_{k}}\right)^{k}}
$$

где $R_{k}$ - эфффект от закупки материальных средств (услуг) в $k$ - м временном периоде (году, полугодии, квартале, месяце), руб.;

$i_{e_{k}}$ - ставка дисконта в $\boldsymbol{e}$ - м подпериоде $k$ - го временного периода (года);

$m_{k}$ - число периодов (месяцев, кварталов) фиксации ставки дисконта в $k$ - м временном периоде (году);

$Z_{k}$ - затраты на эксплуатацию (ремонт, утилизацию и др.) в $k$ - м временном периоде.

3. Расчет базовой цены продукции с применением методов сравнительного подхода. который основывается на сопоставлении с аналогом, не имеющим параметрических отличий от поставляемого вида материальных средств или услуг, и сравнения с аналогом, имеющим параметрические (функциональные) и конструктивные (технологические) отличия от поставляемой продукции или услуг.

$$
E_{t}=E_{t}^{a n}\left(\frac{x}{x_{a n}}\right)^{b}
$$

где $E_{t}^{a n}$ - цена нового аналога на момент времени $t$ в месте закупки материальных средств или услуг данного вида, руб.;

$X$ и $X_{a n}$ - значения функциональной или конструктивно-технической характеристики материального средства (услуги) и его аналога соответственно;

b - показатель, характеризующий коэффициент торможения цены в зависимости от различий между закупаемым материальным средством (услугой) и аналогом по величине основного параметра (вычисляется с применением методов статистического моделирования).

4. Расчет итогового значения базовой цены на основе согласовании значений, полученных на предыдущих этапах

$$
\mathrm{C}=\sum_{i=1}^{n} \alpha_{i} c_{i}
$$

где $c_{i}$ - базовая цена вида материальных средств (услуг), определенная по $i$-му подходу (затратному, сравнительному, доходному), руб.;

$\alpha_{i}$-весовой коэффициент $i$-го подхода к определению базовой цены.

5. Расчет итогового значения базовой цены с учетом с учетом условий поставки материальных средств, продукции (услуг).

При $100 \%$ предоплате

$$
\begin{aligned}
& c_{i j}=c_{i j}^{\text {факm }} /(1+\gamma)^{w} \\
& c_{i j}=\left(1-\sum_{v=1}^{w} d_{v}\right) c_{i j}^{\text {факm }}+\sum_{v=1}^{w} d_{v} c_{i j}^{\text {фaкm }}(1+\gamma)^{v},
\end{aligned}
$$

При оплате в рассрочку

где $c_{i j}^{\text {कaкm }}$ - цена продукции при оплате по факту поставки;

$w$ - количество периодов отсрочки при оплате продукции (месяц, квартал и т.п.);

$d_{v}$ - доля цены, подлежащая уплате в $v$-м периоде;

$\gamma$ - ставка дисконта.

Рис. 1. Укрупненный алгоритм согласования базовой цены 


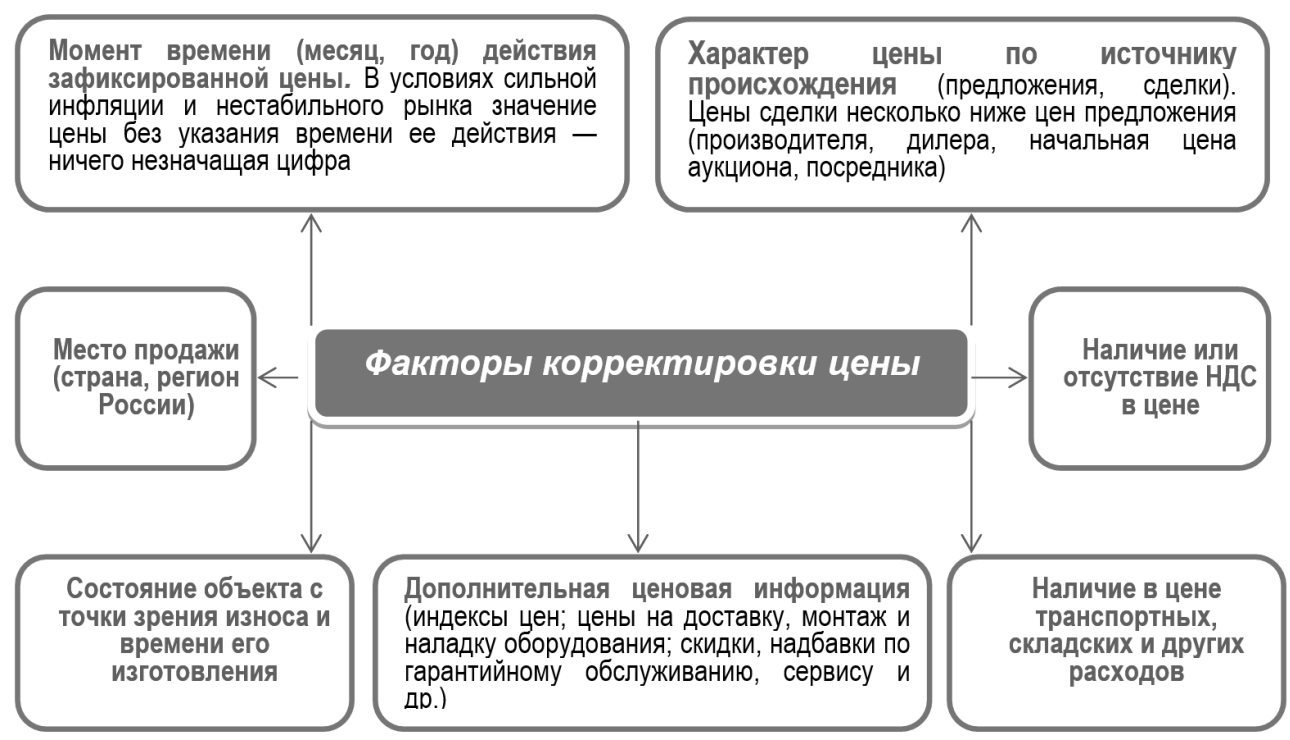

Рис. 2. Основные факторы корректировки цены аналога при определении базовой цены на материальные средства и услуги, поставляемые в СМТО.

На третьем этапе осуществляется расчет базовой цены материальных средств или услуг, поставляемых в СМТО, методом сравнительного (аналогового) подxода.

При этом необходимо учитывать две характерные ситуации: сопоставление с аналогом, который не имеет параметрических отличий от поставляемого вида материальных средств или услуг, и сравнения с аналогом, имеющим параметрические (функциональные) и конструктивные (технологические) отличия от поставляемой продукции или услуг.

Для сравнения с аналогом, не имеющим параметрических отличий в его цену необходимо вносить корректировки из трех следующих групп:

1. по времени (индексация);

2. по условиям продажи;

3. связанные с учетом НДС.

Основные факторы корректировки цены показаны на рис. 2.

При определении базовой цены на материальные средства или услуги $E_{t}$ на основе сравнения с аналогом, имеющим параметрические и другие отличия, в цену аналога необходимо внести кроме «коммерческих» корректировок, корректировки на параметрические отличия. Они подразделяются на коэффициентные и поправочные [1].

Коэффициентные корректировки предлагается применять для учета различий по главным параметрам, из- менение которых сопровождается изменением многих других параметров. Предполагается, что связь между данным параметром и ценой носит нелинейный характер. В общем виде она может быть представлена следующей зависимостью

$$
E_{t}=E_{t}^{a n}\left(\frac{x}{x_{a n}}\right)^{b},
$$

где $E_{t}^{a n}$ - цена нового аналога на момент времени $t$ в месте закупки материальных средств или услуг данного вида, руб.;

$X$ и $X_{a n}$ - значения функциональной или конструктивно-технической характеристики материального средства (услуги) и его аналога соответственно;

$b$ - показатель, характеризующий коэффициент торможения цены в зависимости от различий между закупаемым материальным средством (услугой) и аналогом по величине основного параметра (вычисляется с применением методов статистического моделирования).

В случае отсутствия статистических данных по аналогичным материальным средствам можно применить следующие корректировки цены аналога для определения цены конкретного вида закупаемых материальных средств (услуг) [2]:

корректировка на отличие функциональных и конструктивно-технических характеристик по одному или нескольким параметрам;

абсолютная поправка к цене при одном или нескольких отличающихся параметрах. 
Корректировка ичень закупаемого вида материальных средств (услуг) на отличие по одному параметру заключается:

1) в подборе двух аналогов с учетом промежуточного положения закупаемого вида материальных средств по отличающимся параметрам между аналогами.

2) расчете коэффициента торможения для отличающегося параметра по формуле

$$
b=\frac{\lg \left(\frac{E_{t}^{2}}{E_{t}^{1}}\right)}{\lg \left(\frac{x_{t}^{2}}{x_{t}^{2}}\right)}
$$

где $E_{t}^{1}$ и $E_{t}^{2}$ - цена первого и второго объектов-аналогов в момент времени $t$, соответственно, руб.;

$X_{t}^{I}$ и $X_{t}^{2}$ - значение функциональных и конструктивно-технических характеристик у первого и второго объектов-аналогов в момент времени $t$, соответственHo.

3) расчете базовой цены данного вида материальных средств (услуг) по формуле (3).

Корректировка иены закупаемого вида материальных средств (услуг) на отличие по нескольким параметрам заключается в выполнении следующих действий:

1) подбор двух аналогов с учетом промежуточного положения закупаемого вида материальных средств по каждому отличающемуся параметру между аналогами;

2) расчет коэффициента торможения цены $b_{n}$ для отличающегося параметра по формуле

$$
b_{n}=\frac{\lg \left(\frac{E_{t}^{2}}{E_{t}^{1}}\right)}{\lg \left(\frac{X_{t, a n, n}^{2}}{X_{t, a n, n}^{1}}\right)^{1}}
$$

где $X_{t, a n, n}^{1}$ и $X_{t, a n, n}^{2}$ - значение $n$-го функционального или конструктивно-технического у первого и второго объектов-аналогов в момент времени $t$, соответствен$\mathrm{HO}$;

$n$ - номер функционального или конструктивно-технического параметра сравнения $(n=1, \ldots, 3)$.

3) расчет базовой цены закупаемого вида материальных средств (услуг), отличающегося от известного аналога по трем параметрам

$$
E_{t}=E_{t}^{a n}\left(\frac{x_{t, 1}}{x_{t, a n, 1}}\right)^{b_{1}}\left(\frac{x_{t, 2}}{x_{t, a n, 2}}\right)^{b_{2}}\left(\frac{x_{t, 3}}{x_{t, a n, 3}}\right)^{b_{3}}
$$

где $X_{t, n}$ и $X_{t, a n, n}$ - значение $n$-го функционального или конструктивно-технического у инновационного продукта и объектов-аналогов в момент времени $t$, соответственно.

Абсолютная поправка к цене при одном или нескольких отличающихся параметрах осуществляется в следующей последовательности:

1) подбор двух аналогов с учетом промежуточного положения закупаемого вида материальных средств (услуг) по нескольким отличающимся параметрам (функциональным или конструктивно-техническим) между аналогами;

2) определение цены единицы каждого параметра

$$
v_{n}=\frac{E_{t}^{2}-E_{t}^{1}}{X_{t, 2, n}-X_{t, 1, n}}
$$

где $E_{t}^{l}$ и $E_{t}^{2}$ - цена первого и второго объектов-аналогов в момент времени $t$, соответственно, руб.;

$X_{t, 1, n}$ и $X_{t, 2, n}$ - значение $n$-го функционального или конструктивно-технического у первого и второго объектов-аналогов в момент времени $t$, соответственно;

3) расчет базовой цены закупаемого вида материальных средств (услуг), отличающегося от известного аналога по нескольким параметрам

$$
E_{t}=E_{t}^{a n}+\sum_{n=1}^{k} v_{n}\left(X_{t, n}-X_{t, a n, n}\right) .
$$

Следует сказать, для сравнительного подхода применяют документально подтвержденную ценовую информацию на аналоги, т.е. оперируют все теми же ценами предложения. При этом завышение результатов определения базовой цены умеренное.

Таким образом, каждый из подходов к оценке базовой цены имеет свои преимущества и недостатки, ввиду чего возникает необходимость согласования полученных результатов для определения компромиссной и наиболее достоверной итоговой базовой цены закупаемых материальных средств (услуг) в CMTO.

На четвертом этапе рассчитывается итоговое значение базовой цены. Расчет заключается в согласовании ее значений, полученных на предыдущих этапах. С этой целью применяется формула для определения средневзвешенной величины базовой цены $(C)$ :

$$
\mathrm{C}=\sum_{i=1}^{n} \alpha_{i} c_{i}
$$


Таблица 3. Шкала качественных оценок подходов к определению базовой цены «1-9»

\begin{tabular}{|l|l|}
\hline Градация результатов сравнения & Значение порядковой шкалы «1-9» \\
\hline Равенство & $1-2$ \\
\hline Незначительное преимущество & $3-4$ \\
\hline Значительное преимущество & $5-6$ \\
\hline Явное преимущество & $7-8$ \\
\hline Абсолютное преимущество & 9 \\
\hline
\end{tabular}

где $c_{i}$ - базовая цена вида материальных средств (услуг), определенная по $i$-му подходу (затратному, сравнительному, доходному), руб.;

$\alpha_{i}$ - весовой коэффициент $i$-го подхода к определению базовой цены.

Для расчета весовых коэффициентов предлагается использовать метод анализа иерархий. При этом матрица парных сравнений альтернативных вариантов определения базовой цены по видам закупаемых материальных средств (услуг) строится на основе шкалы качественных оценок подходов (таблица 3).

Матрицы парных сравнений представляют собой обратно симметричные матрицы, на главной диагонали которых находятся единицы. Заполнение матриц парных сравнений основывается на следующих правилах [3]:

если сравниваемые подходы по анализируемому критерию одинаково предпочтительны, то соответствующий элемент матрицы равен 1;

если один из подходов имеет незначительное превосходство над другим по анализируемому критерию, то соответствующий элемент матрицы равен 3 или 4;

если один из подходов имеет значительное превосходство над другим по анализируемому критерию, то соответствующий элемент матрицы равен 5 или 6;

если один из подходов имеет явное превосходство над другим по анализируемому критерию, то соответствующий элемент матрицы равен 7 или 8;

если один из подходов имеет абсолютное преимущество по сравнению с другим по анализируемому критерию, то соответствующий элемент матрицы равен 9.
Расчет весовых коэффициентов подходов к определению базовой цены к определению итоговой базовой цены выполняется по формуле

$$
\alpha_{i}=\sqrt[n]{\prod_{j=1}^{n} a_{i j}} / \sum_{i=1}^{n} \sqrt[n]{\prod_{j=1}^{n} a_{i j}},
$$

где $a_{i j}$ - элемент матрицы парных сравнений;

$n$ - размерность матрицы парных сравнений.

На пятом этапе рассчитывается итоговое значение базовой цены с учетом с учетом условий поставки материальных средств (услуг).

Необходимо пояснить, что фактические суммарные затраты на закупку и доставку единицы продукции от поставщика $i$ до потребителя $j$ рассчитываются с учетом условий поставки. Для этого при 100\% предоплате может использоваться следующая зависимость

$$
c_{i j}=c_{i j}^{\text {фakm }} /(1+\gamma)^{w} \text {. }
$$

При оплате в рассрочку

$$
c_{i j}=\left(1-\sum_{v=1}^{w} d_{v}\right) c_{i j}^{\text {фaxm }}+\sum_{v=1}^{w} d_{v} c_{i j}^{\text {фaxm }}(1+\gamma)^{v},
$$

где $c_{i j}^{\text {фaxm }}$ - цена продукции при оплате по факту поставки;

$w$ - количество периодов отсрочки при оплате продукции (месяц, квартал и т.п.);

$d_{v}$ - доля цены, подлежащая уплате в $v$-м периоде;

$\gamma$ - ставка дисконта.

Научная новизна методики согласования цен на продукцию и услуги в системе закупок целях организации МТО ВС 
РФ, других войск, воинских формирований и органов заключается в том, что она, в отличие от существующих, основывается не только на экономической информации о нормах расхода и ценах ресурсов, полученной от изготовителя или продавца материальных средств (услуг), а наряду с методами затратного ценообразования учитывает стоимость жизненного цикла закупаемой продукции (услуг) и цены аналогов.
Практическая значимость методики состоит в том, что она позволяет согласовать цены на продукцию и услуги в системе закупок для организации МТО ВС РФ, других войск, воинских формирований и органов с учетом интересов производителей (поставщиков), заказчиков (потребителей) материальных средств (услуг), а также их рыночной стоимости.

\section{ЛИТЕРАТУРА}

1. Головецкий Б.Н. Совершенствование организационно-экономического механизма государственного регулирования производства военной продукции и размещение государственного заказа // Интернет журнал «Науковедение».— 2016.— Том 8. — № 2. http://naukovedenie.ru/PDF/32EVN216.pdf (доступ свободный).

2. Викулов С.Ф. Экономика военного строительства: эволюция взглядов на проблемы, методы и решения.—- М.: Изд-во Граница. — 2013.

3. Постановление Правительства Российской Федерации от 11 августа 1955 года № 804 «0 военных представительствах Министерства обороны Российской Федерации».

4. Бабенков В.И., Бабенков А.В. Задачи и направления совершенствования интегрированной системы материально-технического обеспечения с применением современных логистических концепций // Вооружение и экономика. - 2014.— № 3 (28). — С. 75-80.

5. Булгаков Д.В. Теория и методология организационного проектирования системы управления тылом силовых структур государства. Автореферат дисс. докт. экон. наук.-СПб.: СПбГУЭФ. 2007.

6. Бабенков В.И., Афанасьев М.В., Бабенков А.В. Механизмы взаимодействия государства и бизнеса по приоритетным инновационным проектам // Научно-технические ведомости СПбГУ. Экономические науки. — 2015. — № 1 (211). — С. 102-110.

7. Карлик А.Е. Оборонная промышленность как драйвер российской экономики «Форсайт Россия»: новое производство для новой экономики. Том $1 \backslash$ Сборник материалов СПб международного экономического конгресса (СПЭК - 2016) -М.: ИНИР, Культурная революция. 2016. С. 69-93.

8. Бахарев В.В., Капустина И.В., Кириллова Т.В., Переверзева Т.А., Степанова Т.В. Цены и ценообразование на потребительских рынках. СПб.: Национальный информационный канал, 2021.- 178 с.

9. Богатырева С.В., Титов А.Б., Куприянова М.Ю. Экономическая эффективность как основа формирования управленческих решений // Экономика и менеджмент систем управления. - 2016.- - Т. 20.— № 2.1.—С. 116-122.

10. Котляров И.Д. Алгоритм отбора аутсорсеров по критерию способности обеспечить целевые значения показателей, описывающих передаваемый процесс // Проблемы экономики и управления нефтегазовым комплексом. — 2012.— № 10.—C. 50-54.

11. Курбанов А.Х., Логачева А.И. Обоснование показателей военно-логистических процессов в системе материально-технического обеспечения военных потребителей // Вестник Военной академии материально-технического обеспечения им. генерала армии А.В. Хрулева.— 2018.— № 4. — С. 18-23.

12. Топоров А.В., Бабенков В.И. Обоснование критериев оценки военно-экономической эффективности процессов материально-технического обеспечения войск (сил) // Известия Российской академии ракетных и артиллерийских наук. - 2017.— № 1. — С. 23-28.

13. Целыковских А.А., Курбанов А.Х., Плотников В.А. Система материально-технического обеспечения военной организации государства: особенности функционирования и перспективы развития в современных экономических условиях // Управленческое консультирование.— 2014 . — № 12.— C. 16-28.

14. Дубовский В.А., Курбанов А.Х., Плотников В.А. Методическая основа мониторинга функционирования системы контрактов полного жизненного цикла в интересах военной организации государства: организационные, технико-экономические и логистические аспекты // Вопросы оборонной техники. Серия 16: Технические средства противодействия терроризму. - 2019. - № 11-12. - С. 15-22.

15. Дубовский В.А., Курбанов А.Х., Плотников В.А. Сетевая модель планирования и управления процессами жизненного цикла вооружения и военной техники: процедура построения и реализации // Известия Российской академии ракетных и артиллерийских наук. - 2020.— № 3.—C. 39-45. 